\title{
APONTAMENTOS PARA UMA POÉTICA DA TRADUÇÃO DE HISTORIADORES GREGOS
}

\author{
Breno Battistin Sebastiani* \\ Universidade de São Paulo
}

\begin{abstract}
Resumo: O artigo se estrutura em duas seções: na primeira, discuto premissas teóricas que orientam minha prática de tradução de historiadores gregos. Na segunda, apresento exemplos concretos de traduções (parágrafos de Heródoto, Tucídides e Políbio) que indiciam brevemente a concretização de tais premissas.

Palavras-chave: Tradução de prosa. Tradução de narrativa. Tradução de historiografia grega.
\end{abstract}

\section{OUTLINES FOR TRANSLATIONS' POETICS OF GREEK HISTORIANS ${ }^{1}$}

\begin{abstract}
This paper has two sections. The first discusses some theoretical assumptions that guide my practice in translating Greek historians. In the second one, I present specific examples of translations (paragraphs from Herodotus, Thucydides and Polybius) which briefly indicate the realization of such assumptions.

Keywords: Prose translation. Narrative translation. Greek historiography translation.
\end{abstract}

\footnotetext{
* Breno Battistin Sebastiani: Doutor (2006) e Mestre (2002) em História Social pela Universidade de São Paulo (USP). Bacharel e Licenciado (1999) em História pela mesma universidade. Livre-docente (2016) da Universidade de São Paulo. Professor Associado de Língua e Literatura Grega e docente permanente da Pósgraduação em Letras Clássicas da Universidade de São Paulo. São Paulo, São Paulo, Brasil. E-mail: sebastiani@usp.br

${ }^{1} \mathrm{O}$ presente trabalho foi realizado com apoio do $\mathrm{CNPq}$, Conselho Nacional de Desenvolvimento Científico e Tecnológico - Brasil.
} 
Mi si presentano due maniere di tracciare la strada. La prima maniera consisterà nel rispettare i limiti dei poderi, nel contornare i cascinali, nel varcare il fiume nel punto più stretto, nel lasciare intatti cappelle, frantoi, mulini, pozzi, officine, campi sportivi, nell'evitare le zone paludose e quelle rocciose.

(A. Moravia, L'uomo come fine)

Além da historiografia de Políbio, cujos cinco primeiros livros traduzi e estão em vias de ser publicados, tenho com frequência realizado traduções de outros historiadores antigos, de variável extensão, para uso em trabalhos acadêmicos - nomeadamente, de Herótodo, Tucídides e Tito Lívio. Para além da indispensável atenção constante às peculiaridades do estilo de cada um, sempre que publico trechos traduzidos tenho em mente algumas premissas teóricas mais amplas, que norteiam a minha prática de (re)leitura desses textos e configuram minha atividade como tradutor.

É de tais premissas que tratarei no presente trabalho, tão somente procurando alinhavar sugestões que permitam pensar a tradução de historiadores antigos como uma operação poética, isto é, recriadora de significantes, fruto de colaboração com o original, e não como suposto espelhamento fidedigno. Ao final, acrescento três exemplos com base nos quais tentarei alinhavar os conceitos discutidos.

Penso a construção da narrativa historiográfica antiga ou atual como uma forma de tradução intersemiótica do real ${ }^{2}$, como tecelagem artesanal que alinhava distintos fios pacientemente selecionados e com os quais o narrador transpõe o real - pessoas, situações, relacionamentos, objetos etc. - para texto com sentidos permanentemente interconectados e interconectáveis. Em outros termos, como operação significante cujos significados se realizam na contemporaneidade da experiência do leitor e configuram um "objeto transicional" (a expressão é de LIMA, 2006, p. 289).

2 A respeito da noção de "tradução intersemiótica" e "tradução como forma", cf. respectivamente SELIGMANN-SILVA, 2014, p. 229 e 2011, p. 28, além da coletânea de textos de Haroldo de Campos organizada por TÁPIA; NÓBREGA, 2013. 
Tal reflexão decorre de um primeiro cruzamento entre teorias da história e teorias da tradução, o que sempre me pareceu mutuamente fecundo. Quando traduzo, tento reanimar a centelha presente na meditação de B. Croce conhecida mais pela fórmula "ogni vera storia è storia contemporanea" do que pelo questionamento que a constela de significados:

quale l'interesse presente della storia che narra la guerra peloponnesiaca o la mitridatica, le vicende dell'arte messicana o della filosofia arabica? Per me, in questo momento, nessuno: e quindi, per me, in questo momento, quelle storie non sono storie, ma, tutt'al piú, semplici titoli di libri storici: e sono state o saranno storie in coloro che le hanno pensate o le penseranno, e in me, quando le ho pensate o quando le penserò, rielaborandole secondo il mio bisogno spirituale. - Se, invece, ci atteniamo alla storia reale, alla storia che realmente si pensa nell'atto che si pensa, sarà agevole scorgere che essa è perfettamente identica alla piú personale e contemporanea delle storie ${ }^{3}$. (CROCE, 1920, p. 5)

Ainda mais antigo é o truísmo segundo o qual todo trabalho, meditação ou narrativa são filhos de seu tempo - são históricos. A pressuposição de escapar à própria contemporaneidade, subjetividade e/ou mediação, bem como ao caráter (re)construtor de toda leitura - tanto faz se por ingenuidade ou compromisso - conota sempre outro modo de indiciá-los. Toda tradução, sobretudo a de textos clássicos, não deixa de ser uma forma de recepção que precisa levar em conta, no seu operar cotidiano, as diversas camadas de mediações históricas, políticas, culturais etc que se acumularam e contribuíram para a constituição de cada percepção contemporânea

${ }^{3}$ A primeira edição, em alemão, é de 1915; em italiano, de 1917. 
do fenômeno (MARTINDALE; THOMAS, 2006) - a ambivalência da última oração é proposital.

Não apenas a distância cronológica, linguística e cultural enorme entre nós e eles, mas sobretudo o trabalho metabólico com a linguagem em todos os níveis (metaplástico, metatático, metasememático e metalógico $)^{4}$ operado por exímios narradores como Heródoto e Tucídides, por exemplo, me obrigam a pensar sua releitura como uma constante "compensação tradutória", conforme teorizado por A. Scatolin (SALÚSTIO, 2015, p. 93-94) em sua recém-publicada tradução de Salústio, isto é, como tentativa de recriar na e pela tradução efeitos análogos aos presentes no original.

Outro modo de dialogar com os textos antigos tentando equacionar o problema da intraduzibilidade (do ponto de vista da fidelidade) entre o grego clássico e o português encontrei nos trabalhos de C. Romano (2010) e M. Jay (2011). Embora nenhum dos dois tenha por preocupação explicitamente a teoria da tradução, seus textos contêm diversas meditações fecundas que permitem pensar a tradução como relação, diferença e possibilidade hermenêutica, antes que aspiração à semelhança.

M. Jay, por exemplo, considera que "[t]o the extent that an event is irreducible to its enabling context, intellectual or artistic events are also best grasped in terms of what they make possible rather than what makes them possible" (2011, p. 566). Este ponto, por sua vez, se baseia explicitamente no trabalho de C. Romano:

[f]or the historian, the upshot of all this is that for the class of extraordinary happenings that justify the label 'event' - and it seems likely they are a small, if significant, minority-contextual explanation, however we construe it, is never sufficient. As Romano puts it, 'understanding events is always apprehending them on a horizon of meaning that they have opened

${ }^{4}$ Emprego tais terminologias conforme DUBOIS, 1974. 
themselves, in that they are strictly nonunderstandable in the light of their explanatory context' (EW 152). If this is true for events in general, it is perhaps more so for those we might call events in intellectual history. (idem, p. 567).

Já a ideia de "possibilidade hermenêutica" forjei a partir da inversão sugerida por C. Romano:

loin que ce soit l'intention de l'auteur qui nous fournisse la clé de l'interprétation du texte, c'est exactement l'inverse qui est le cas: c'est seulement une fois que nous avons compris le texte, que nous avons saisi ce qu'il veut dire, que nous comprenons aussi et par là même ce que l'auter a voulu dire en l'écrivant; c'est la signification du texte qui nous donne accès à ce qui était intentionnel dans le fait de l'écrire et nullement l'inverse. Par conséquent, loin que l'intention, entendue en ce sens, puisse nous fournir le moindre 'critère' d'une bonne compréhension du texte, c'est bien plûtot en comprenant le texte que nous comprenons aussi l'intention de l'auteur entendue en ce sens, c'est-à-dire ce qu'il y avait d'intentionnel dans le fait de disposer les mots dans cet ordre et non autrement. Bref, pour pouvoir dire ce que l'auteur a dit intentionnellement, il est nécessaire de dire ce que nous avons compris du texte, même si dire ce que nous avons compris du texte ne suffit pas toujours pour établir ce que l'auteur a dit intentionnellement. (2010, p. 74, destacado no original).

Por outras palavras, minha abordagem tradutória procura levar em conta, antes de tudo, percepções contemporâneas sobre um 
determinado historiador, sempre conscientes de que o passado só é apreendido enquanto recriado. No caso da tradução de Políbio, por exemplo, a que me dediquei por oito anos, por vezes me vi na necessidade de equacionar problemas como os apontados recentemente por outro estudioso do historiador aqueu, J. Thornton (2013). Para o estudioso italiano, "l'attenzione prestata agli aspetti letterari delle Storie comporti il rischio di sottovalutare il significato del messaggio politico che Polibio intendeva trasmettere, distogliendo così l'attenzione dei lettori dalla riflessione sugli imperi, in cui pure si era riconosciuto l'elemento principale, almeno sul piano del contenuto, dell' 'attualità' di Polibio, della sua rilevanza per i lettori di oggi" (THORNTON, 2013, p. 828) ${ }^{5}$. Thornton descola os aspectos literário e político da obra de Políbio, destacando o teórico da história do estratego, ao passo que tento pensá-los entrelaçados, como índice um do outro com consequências para a redação da narrativa e, por implicação, da tradução.

Antes de discutir exemplos de como penso minha prática de tradução, proporei a meditação de uma cena do filme Malèna (dir. G. Tornatore, 2000) como contraponto analógico. O pai de Renato Amoroso, sabemos logo no início da trama, não apreciava Mussolini, aversão não plenamente compreendida, mas partilhada pelo filho. À altura do meio da narrativa, o garoto culpa o ditador por uma das tantas decepções envolvendo Malèna. O gesto é tão instintivo e fortuito quanto eloquente e promissor. Numa trama em que a música e o silêncio da protagonista formam acordes que aspiram ao sublime, um deles é particularmente notável. Durante uma aula de grego, a professora declama o canto das sirenas (Od.12.184-191), cujos primeiros versos são nitidamente audíveis. A voz dela, entretanto, vai emudecendo conforme o garoto entra a devanear, enxergando no lugar da mestra a amada, de cuja boca ouve claramente apenas a última palavra: poulyboteíre ([a [terra] que a muitos

\footnotetext{
${ }^{5}$ Juízo que o leva a concluir, então, às p. 836 e sobretudo 842: "Polibio dunque non è un letterato, un 'intellettuale' o un artista. Facendone un teorico della storiografia, secondo una tradizione che in Italia può farsi risalire a Benedetto Croce, o un abile narratore, lo si assimila indebitamente a modelli contemporanei, estranei alla sua attività".
} 
nutre[). Rompida a ilusão pela mestra enfurecida, o menino expulso da sala desce correndo as escadarias e derruba furioso um busto do ditador que atravancava o trânsito entre dois lances. O estorvo inútil é rachado contra o chão e as duas metades ocas jazem frente a frente tautológica e especularmente.

Mesmo ao longo desse mo(vi)mento aparentemente residual na trama, é notável o diálogo entre ética e estética comum tanto ao filme quanto à narrativa do historiador antigo. $\mathrm{O}$ canto das sirenas reverbera precisamente o cenário mithistórico da Odisseia onde se passa a trama do filme, cenário também meticulosamente estudado por Políbio em diversos trechos da História pragmática (9.16, 12.27a-28, 34.2-4). Antes que por contingências acessórias e fortuitas, o canto das sirenas irmana as três narrativas - da Odisseia, de Políbio e do filme - de modo bastante mais incisivo. A personagem amada por Renato, tão respeitada quanto anelada, significante e esquiva, não deixa de ser também um canto de sirena análogo aos anseios de Políbio - que aspira a um conhecimento universal (Plb.1.4) - talvez igualmente pensados para "a muitos nutrir", realizações político-estéticas que não prescindem, antes pressupõem, arraigamento ético dos problemas envolvidos, algo evidente desde as implicações do prólogo do historiador e ao longo de toda a obra (e.g., 1.14 e 1.35) sobre a qualificação e responsabilidade na emissão de juízos. Enquanto preso ao banco da escola, como Odisseu atado ao mastro, por muito pouco Renato não perde a si mesmo. A situação é semelhante à do historiador que, a despeito de escrever no exílio, nunca deixou de aspirar ao poder perdido e se consumiu na dedicação ao Dimpulso de salvar o passado como algo vivo que só se acalma na arte, à qual a própria história pertence enquanto representação da vida passada" ${ }^{\text {. }}$

${ }^{6}$ A formulação de Adorno e Horkheimer, que se encontra na Dialética do esclarecimento (ADORNO, 2003, p. 558), é central para a compreensão da atitude de Odisseu quanto à dominação associada à autoconservação. Enquanto o herói emblematiza o patriarca burguês esclarecido, suas atitudes enformam uma "alegoria da dialética do esclarecimento" (2003, p. 558-606; a última expressão está na p. 560). 
O que o filme escancara, e que é notável também nos textos dos historiadores antigos, impactando diretamente a prática do tradutor, é a indissociação das dimensões ética e estética, que se nutrem uma à outra em permanente diálogo. Ao invés de se distinguirem como forma e conteúdo ou meios e fins, ética e estética, ao contrário, definem uma unidade: “a work's moral outlook, if it has anything so cohesive, may be secreted as much in its form as its content -that the language and structure of a literary text may be the bearers and progenitors of so-called moral content" (EAGLETON, 2012, p. 46). Caberia ao tradutor, então, a percepção do vínculo e a tentativa de preservar suas implicações no texto de chegada, caso esteja trabalhando com um que o permita.

$* * *$

A título de exemplos, apresento inicialmente traduções minhas dos parágrafos 3.14 de Heródoto, 1.22 de Tucídides e 1.4 de Políbio:

No décimo dia após tomar as muralhas de Mênfis, Cambises alojou nos arredores Psamenito, rei dos egípcios havia seis meses, para insultá-lo. Depois de alojá-lo na companhia de outros egípcios, decidiu testar-lhe o ânimo fazendo o seguinte: vestiu de escrava a filha do rei e mandou-a buscar água carregando um jarro. Selecionou e enviou outras virgens, filhas dos homens mais ilustres, junto da filha do rei. Conforme as virgens gritavam e lamentavam ao passar diante dos pais, todos gritavam de volta e choravam, vendo a humilhação das filhas. Psamenito, porém, olhou, reconheceu a filha e baixou a cabeça. Passadas as aguadeiras, em seguida Cambises enviou o filho do rei seguido por dois mil egípcios de mesma idade, todos com arreios no pescoço e freios na boca. Eram levados como reparação pelos mitilênios e pela nau perdidos em Mênfis. Assim os juízes reais haviam sentenciado: para cada homem 
deveriam ser abatidos dez dentre os mais ilustres egípcios. Ao ver o cortejo e reconhecer o filho condenado à morte, o rei fez o mesmo que diante da filha, enquanto os demais egípcios à sua volta choravam e praguejavam. Depois que passaram, um ancião que fora comensal do rei, havia perdido todos os bens, estava paupérrimo e esmolava pelo exército, cruzou o caminho de Psamenito, filho de Amásis, e dos egípcios que naquelas cercanias se encontravam. Assim que o viu, Psamenito caiu em pranto, chamou o amigo pelo nome e golpeou a cabeça. Os guardas que o vigiavam relatavam a Cambises todas as suas reações à passagem de cada cortejo. Espantado com tais reações, Cambises mandou um mensageiro para interrogá-lo: "o rei Cambises te pergunta, Psamenito, por que, ao ver a filha humilhada e o filho marchando para a morte, não gritaste nem choraste, mas honraste o mendigo, que nenhuma relação tem contigo, conforme o rei soube por terceiros". Um assim perguntou, o outro respondeu: "ó filho de Ciro, os males familiares são grandes demais para me fazerem chorar. Já o infortúnio de um amigo é digno de lágrimas - um homem que chegou ao limiar da velhice depois de passar da abundância e prosperidade à indigência". Diz-se que, quando a resposta foi reportada e ouvida, a corte aprovou-a. Contam os egípcios que Creso chorou (pois ele havia seguido para o Egito com Cambises), como também choraram os persas presentes; que o próprio Cambises foi invadido pela compaixão, mandando imediatamente que o filho do rei fosse resgatado de entre os condenados e Psamenito trazido de onde estava à sua presença (Hdt.3.14).

Esse parágrafo é o passo de Heródoto que W. Benjamin refere como "a verdadeira narrativa" (1987, p. 203-204), que "não se entrega" e conserva a potência de despertar reflexões a despeito de seus 2500 anos. Do ponto de vista do tradutor, a brevidade, a coloquialidade e, sobretudo, a conjunção perfeita entre ritmo e conteúdo de "causo" são o que exige, imagino, a recriação por parte do tradutor. Além disso, há que se tentar transpor também algo do dialeto jônico em que Heródoto escreveu, com- 
preensível para todos os gregos, mas nem por isso menos linguisticamente marcado. Como, entretanto, uma tradução para formas excessivamente coloquiais poderia se prestar a equívocos em português, preferi salpicar o texto preservando termos algo desusados ("aguadeira", "arreio", "freio", "cercania") bem como a segunda pessoa do singular, uma vez que, em relação ao grego ático do século V a.C., variante usada na Atenas em que viveu Heródoto, seu dialeto natal jônico pode ser dito arcaico.

Quanto pronunciou cada um que estava na iminência de combater ou já nela engajado, foi-me difícil recordar a exatidão mesma do que foi dito e que eu mesmo ouvi, ou quando me foi reportado por terceiros. Tal qual me pareceu próprio do que cada um tenha falado em cada circunstância, a mim que me mantinha o mais próximo do conteúdo global do que foi realmente proferido, assim está dito. Decidi relatar as ações praticadas na guerra não porque me informasse junto a qualquer um, nem como bem me parecessem, mas examinando uma a uma, em toda precisão possível, aquelas às quais eu mesmo estive presente e as que soube de terceiros. Descobrir é difícil, porque cada um dos presentes às ações não diziam o mesmo sobre elas, mas conforme simpatizava com cada parte ou recordava. Talvez o caráter não mítico delas se mostre pouco agradável à audiência; mas quantos desejarem examinar o que do passado é evidente e que há de ser igual ou semelhante no futuro, segundo a humanidade, isso bastará para distinguir a obra como útil. Ela foi composta como aquisição perene, mais do que como declamação de circunstância (Th.1.22).

Já esse parágrafo de Tucídides apresenta outras peculiaridades, mas me concentrarei em duas. Primeira, a sugestão notável, vazada num estilo que ambiciona sugerir a maior precisão e concisão, de uma teoria da narrativa historiográfica que, mutatis mutandis, poderia ser transposta quase que integralmente como teoria da tradução. Segundo, a polissemia da última frase. Se considerada a "metáfora de um ktêma para ser ouvido", conforme a leitura proposta por S. Rocha (2008, p. 45-48), a última 
frase comportaria também a seguinte tradução: "aí está [a obra], para se ouvir mais como aquisição perene (ktêmá te es aiei) do que declamação de circunstância". Subsumi o verbo "ouvir" (akoúein) em minha tradução menos para evitar uma decisão entre "leitura em voz alta" ou "em silêncio" do que tentando preservar a indeterminação do original - fundamental para sinalizar ao tradutor um critério de recepção, ao indiciar o público potencial da obra. Quanto ao dialeto, Tucídides emprega como base o ático hoje dito padrão, corrente na Atenas dos séculos V e IV a.C. Seu idioleto, entretanto, é particularíssimo, carregado de idiossincrasias sintático-semânticas e tours de force como o da metáfora mencionada.

O que é peculiar à nossa obra e espantoso em nossa época é isto: assim como o acaso fez convergir quase todos os acontecimentos do mundo habitado para um único centro e fez com que tudo se voltasse para um único e mesmo objetivo, do mesmo modo é preciso levar aos leitores, pela história e sob uma única visão sinóptica (sýnopsin), a manobra de que o acaso se serviu para realizar a interação dos fatos. Foi sobretudo isso o que nos desafiou e incitou para o projeto da história, bem como o fato de que ninguém, em nossa época, empreendeu tratar desses fatos por completo (syntáksei); se o tivesse, muito menor seria minha ambição nesse sentido. Ora, vendo que muitos se dedicam a guerras específicas e a alguns fatos concomitantes, mas que ninguém se pôs a examinar, ao que sabemos, a ordenação geral dos eventos - quando e onde começaram, e como terminaram (syntéleian) $\mathrm{\square}$, considerei absolutamente necessário não negligenciar nem deixar que passesse sem estudo a mais bela e proveitosa empresa do acaso. Pois ele, frequentemente inovador e continuamente (synekhôs) jogando com a vida humana, jamais realizou, em uma palavra, tal façanha, nem disputou um jogo como em nossa época. Assim, dos escritores de histórias parciais não é possível obter uma visão de conjunto (synideîn), senão qualquer pessoa suporia compreender imediatamente a configuração de todo o mundo habitado, bem como seu ordenamento e disposição gerais (sýmpasan), depois de percorrer uma a uma as cidades 
mais ilustres ou, por Zeus, depois de vê-las destacadas em um mapa, algo de modo algum verossímil. Parece-me que padece de algo semelhante quem acredita que por meio de uma história parcial terá adequada visão de conjunto (synópsesthai), como se, ao ver desmembradas as partes de um corpo antes vivo e belo, pensasse ter se tornado efetivamente testemunha da vitalidade e da beleza de um ser vivo. Se alguém recompusesse (syntheis) e reconstruísse o mesmo ser dando-lhe a forma e a aparência de um que vive, e em seguida novamente o mostrasse àquele indivíduo, penso concordaria rapidamente que antes se afastava muito da verdade e se portava como quem sonhava. Pelas partes é possível ter noção do todo, mas não ciência e juízos sólidos. Por isso deve-se considerar a história parcial totalmente superficial se comparada (symbállesthai) ao conhecimento e à credibilidade derivados da história universal. Apenas pela coesão (symplokês) e justaposição de todos os elementos em relação uns aos outros, e ainda por sua semelhança e diferença, é possível apreender a utilidade e o prazer da história após uma visão geral (Plb.1.4).

Com relação a esse parágrafo de Políbio, reproduzi entre parênteses todos os vocábulos originais construídos com a conjunção syn- (port. com-), fundamental não apenas para a semântica do passo como, sobretudo, do modo de pensar aglutinante, compacto, do historiador, que não economiza palavras nem encadeamentos frasais. Em metade das situações consegui manter equivalentes em português que preservassem a possibilidade hermenêutica; na outra metade, tive de recorrer a compensações servindo-me de locuções que reaparecerão em outros passos-chave da narrativa - caso, por exemplo, de "visão sinóptica e/ou de conjunto". O ponto central não é o ter ou não reproduzido a visão de Políbio, mas a tentativa de transferir, mediar, criar no pensamento do leitor correspondências da ação sugerida. Se nenhum historiador cria fatos, recria, contudo, as tensões e fraturas do real que vivencia. No caso do parágrafo acima, o acúmulo de vocábulos em syn-; a sintaxe particularmente cumulativa; 
a ambição de alçar-se ao ponto de vista divino; e a insistência no "papel do acaso" (týkhe) na (in)determinação dos eventos narrados, isto é, insistência em uma acepção específica de "acaso" - todos esses fatores somados talvez remetam a uma significação almejada pelo autor e que cabe ao tradutor tentar captar e converter. Se, por um lado, o fato de se tratar de um texto em prosa narrativa poderia sugerir que a tarefa é relativamente simples, por outro lado o mesmo argumento serviria como complicador, dada a necessidade de, ao mesmo tempo, tentar preservar o estilo do autor sem, contudo, ultrapassar os limites do português. O que nos obriga considerar brevemente algumas peculiaridades do estilo de Políbio.

A língua em que Políbio escreveu foi uma espécie da koiné [língua franca] helenística que já foi designada como "jargão de chancelaria", de fraseado semelhante ao de documentos oficiais e equidistante da reação aticista e do asianismo pomposo. Sua sintaxe e estilo são claros, embora por vezes empolados: repete construções com frequência, de modo quase formular; não hesita em encadear frases excessivamente longas; e tem especial apreço por expressões vagas, triviais e pleonásticas. Para um tradutor que pensa o próprio ofício de modo análogo ao das frequentes exortações de Rosa a Curt Meyer-Clason e Edoardo Bizzarri, isto é, como colaboração criativa; mas, ao mesmo tempo, sem poder dispor das opiniões e aconselhamentos de um autor vivo e, bem ao contrário, tendo de lidar com uma massa crítica erudita que por vezes parece ultrapassar o acervo de uma biblioteca, tentei estabelecer algo como uma "negociação" com o historiador aqueu. Preservei tais ocorrências na tradução apenas quando estritamente imprescindíveis, e redibvidi períodos do original quando sua manutenção comprometeria o entendimento ou a fluência do português. Não busquei nem um texto desnecessariamente helenizado - o que, no caso de Políbio, descambaria para um pedantismo tedioso - , nem um texto tranquilamente fluido, porém que em nada lembrasse o original.

Um último exemplo provém também de Políbio, de seu livro 12, inteiramente dedicado à polêmica contra um historiador antecessor, Timeu 
de Tauromênio. A fim de refinar a própria crítica, Políbio acaba por redigir uma série de reflexões fundamentais não apenas para a teoria da historiografia na antiguidade mas - por que não? - da própria prática da tradução, seja antiga ou moderna:

próprio da história é conhecer em primeiro lugar os discursos que foram realmente pronunciados tais quais o tenham sido; em segundo lugar, procurar saber a razão porque o feito ou dito foi ou não bem sucedido, uma vez que o acontecimento em si, narrado de forma sumária, fascina, mas não tem qualquer utilidade, enquanto que, acrescentada a causa, o uso da história se torna frutífero. Se circunstâncias similares forem transpostas (ek gàr tôn homoíon epì toùs oikeíous metapheroménon kairoús) para ocasiões apropriadas, surgem meios e antecipações para se prever o futuro e enfrentar com mais confiança o que sobrevier, ora tomando-se precauções, ora imitando o passado. (12.25b.1-3);

é preciso sempre escolher discursos adequados e oportunos. Uma vez que não há um uso estabelecido que determine quantos e quais, dentre os discursos possíveis, devam ser empregados, é preciso empenho e regras bem diversos se a meta for ser útil aos leitores e não lesá-los. É difícil enunciar o momento oportuno em cada ocasião, mas não é impossível ter uma ideia dele por meio dos princípios derivados da experiência pessoal e da prática. Quanto ao problema em questão, sobretudo o que segue dá margem a reflexão sobre o que estou dizendo: se os historiadores, ao expor ocasiões, inclinações e disposições de quem delibera e, em seguida, os discursos realmente pronunciados, nos explicassem as causas pelas quais os oradores foram ou não bem sucedidos, teríamos uma noção verdadeira do ocorrido e poderíamos alcançar nossos objetivos operando distinções ou transpondo a dita noção para circunstâncias semelhantes (háma mèn diakrínontes, háma dè metaphérontes epì tà paraplésia). (12.25i.6-8). 
Traduzir tais passos é como encontrar-se no ponto central de uma mise en abyme que faz a ponte semiótica entre nós e o passado: é por em prática o que se (re)lê no exato e mesmo instante em que é (re)lido! Ambos os passos tratam da operação que para Políbio seria central em qualquer obra histórica: como narrar e apreender, isto é, como construir relações causais por meio de comparações, atrelando dois ou mais fatos dos quais ao menos um é entendido como causa. Políbio propõe um meio para preencher essa distância entre realidade e discurso histórico e imputar-lhe sentido com base em sua empeiría e no hindsight do leitor. Conhecer razões, fatos e ditos é entendido como recriar na própria mente as intenções e experiências alheias. Antes de prosseguir, convém determo-nos um pouco mais no que entendemos por recriar e no que Políbio teria entendido com o conceito de transferência.

Ambos os passos expõem o cerne do pensamento de Políbio a respeito do sentido de se escrever história e exprimem suas mais explícitas e detalhadas declarações metametódicas (a obra mesma é já seu próprio método), entrelaçando exigências técnicas e posturas éticas pessoais (respectivamente, as normas que propõe ou aceita no escrever história e no ajuizar relações interpessoais). Notável no início de ambos é o entrelaçamento sutil entre os papéis de autores e leitores como agentes de compreensão de textos históricos: os primeiros porque produzem textos, os segundos porque podem colocar em prática o que porventura extraírem da leitura. Fundando-se na própria experiência, os autores poderiam escolher se acrescentariam ou não as causas ou as orações mais adequadas a cada situação. Tal escolha condicionaria a utilidade do relato. Baseando-se na construção textual decorrente da verdadeira realidade (integrada com orações, fatos, oportunidades, causas, razões, experiências pessoais etc), os leitores poderiam realizar escolhas análogas tanto no entender o pensamento do historiador quanto no agir.

As palavras-chave para definir tal entrelaçamento (e os procedimentos cognitivos e criativos nele pressupostos) são os dois particípios de metaphérein nos fechos de ambos os passos, a enuclear a operação descrita. Embora a acepção usual de metaphérein seja a 
retórica, os significados atribuídos por Políbio a tais vocábulos não são exatamente, ou não somente, aqueles retórico-poéticos ("elaborar metáforas", "escrever metaforicamente") ou etimológicos ("transferir mentalmente de um ponto a outro", daí "comparar", "criar analogia"). Nos últimos se encontram também implicações éticas em estreita relação de continuidade. Comparar e transferir envolvem agir coerentemente, de modo que nas atitudes transpareçam os motivos dos agentes. São operações que ocorrem em temporalidades distintas: o presente da escrita não é mais o da vivência e não será jamais o da leitura alheia. Mas é no pressupor a possibilidade de estabelecer semelhanças ou analogias entre circunstâncias e situações, não obstante a passagem do tempo, que se mostra o passo dado por Políbio no entendimento de metaphérein, a novidade e a fecundidade de sua teoria: o historiador não distingue, antes impõe ao sentido discursivo de transferir também um sentido prático. Tal imposição explica, por exemplo, sua exigência de experiência pessoal político-militar a fundar a escrita da história, exigência coerente com sua trajetória de vida. Políbio escreve porque possui experiência; sua escrita é produto da vida e do complexo de inferências analógicas construídas em seu curso. O sentido então atribuído a metaphérein pode ser dito reconstrutivo em acepção rigorosamente pragmática e de modo algum paradoxal: transferir agora significa construir pontes entre reflexão e ação, fecundando uma com a outra continuamente, tornando o agir uma reflexão vivida e o pensar ação meditada ${ }^{7}$. Excluída a questão da exigência de experiência pessoal político-militar, todos os demais pontos do raciocínio do historiador sobre a escrita da história dizem respeito, igualmente, ao ofício do tradutor entendido como operação recriadora.

Tentei, enfim, preservar minha liberdade possível no interior da realidade cultural e textual que se me impunha, tendo sempre em

${ }^{7}$ Examinando o núcleo para onde convergem os procedimentos narrativos que enunciam a dialética entre história e ficção, SOARES, 2013, p. 247 anota: "a metáfora, traço específico da narrativa de ficção, é uma primeira modalidade a auxiliar a refiguração do tempo pela história”. 
mente que a maior contribuição desses historiadores para a medi(t) ação histórica foi ter deixado o próprio texto como fundamento e espelho para analogias alheias. Se a historiografia, como a tradução, são meios, fim há de ser sempre o homem e sua reflexão construtiva.

\section{Referências}

ADORNO, T. W. Gesammelte Schriften. Berlin: Directmedia, 2003.

BENJAMIN, W. Magia e técnica, arte e política. Ensaios sobre literatura e história da cultura. Tradução: S. P. Rouanet. $3^{\text {a }}$ ed. São Paulo: Brasiliense, 1987.

CROCE, B. Teoria e storia della storiografia. $2^{\text {a }}$ ed. Bari: Laterza, 1920.

DUBOIS, J. et al. Retórica geral. São Paulo: EDUSP, trad. C. F. Moisés, D. Colombini e E. Barros, 1974.

EAGLETON, T. The event of literature. New Haven; London: Yale University Press, 2012.

JAY, M. Historical explanation and the event: reflections on the limits of contextualization, New Literary History, Baltimore, n. 42, p. 557-571, 2011.

LIMA, L. C. História. Ficção. Literatura. São Paulo: Cia das Letras, 2006.

Malèna. Direção de Giusepe Tornatore. Produção de: Harvey Weistein et al. Itália; EUA: Medusa Film, Miramax, Pacific Pictures, Tele+, 2000. 109min. 
MARTINDALE, C.; THOMAS, R. F. (Ed.). Classics and the uses of reception. Malden; Oxford; Victoria: Blackwell, 2006.

ROCHA, S. L. R. Logos, writing and persuasion in Thucydides' History. PhD Thesis (Philosophy) - Royal Holloway College, University of London, London, 2008.

ROMANO, C. Compréhension dПun texte et intention dワauteur. In: OUELBANI, M. (Org.). L'intention. Tunis: Université de la Sorbonne Paris IV et Presses de l’Université de Tunis, 2010, p. 57-84.

SALÚSTIO. A conjuração de Catilina. Tradução e organização: Adriano Scatolin. São Paulo: Hedra, 2015.

SELIGMANN-SILVA, M. Vilém Flusser: entre a tradução como criação de si e a pós-tradução, Cadernos de tradução, Florianópolis, n. especial, p. 223-234, 2014.

SOARES, M. T. M. Tempo, mythos e praxis. O diálogo entre Ricoeur, Agostinho e Aristóteles. Porto: Fund. Eng. A. de Almeida, 2013.

TÁPIA, M; NÓBREGA, T. M. (Org.). Haroldo de Campos $\square$ Transcriação. São Paulo: Perspectiva, 2013.

THORNTON, J. Polibio l'artista, Mediterraneo Antico, Pisa-Roma, n. 16.2 , p. 827-842, 2013.

Recebido em: 15/01/2016

Aceito em: 08/04/2016

Publicado em setembro de 2016 